\title{
Streaming Audio Services in Canadian Academic Libraries
}

by

\author{
James Mason and Jared Wiercinski
}

\begin{abstract}
This article looks at the use of streaming audio technologies in Canadian academic libraries. The issues of access, technology, metadata, workflow, and copyright are examined through two case studies: a digital archive of sound recordings at the University of Toronto, and an electronic course reserves system at Concordia University. The results from a survey of Canadian music librarians are presented, which reveal minimal use of streaming audio technologies.
\end{abstract}

KEYWORDS. Academic libraries, audio, digitization, music, streaming

\section{INTRODUCTION}

Streaming media technologies provide a convenient way in which to present and access digital content. Many academic music libraries maintain collections of sound recordings that could benefit from digitization and streaming. This includes content created by their own institutions, such as student or faculty lectures and recitals, as well as the commercial sound recordings (e.g., compact discs, vinyl records) required for the music curriculum. The main motivations to digitize these collections are preservation and improved access; preservation ensures that unique content will remain accessible, and streaming audio technologies offer the possibility of remote, around-the-clock access to collections that may otherwise be underused.

Although offering streaming audio or digital access to library material, either archival or commercial, is becoming more common in the U.S. ${ }^{1}$ and in some parts of Europe such as 
Britain $^{2}$ and The Netherlands, ${ }^{3}$ our survey (see Appendix) suggests that, aside from subscription databases, few music libraries in Canada offer this service. This is unfortunate, since students and faculty increasingly expect the ability to access sound recordings online. The popularity of social networking sites (e.g., Facebook, MySpace, Last.fm), ${ }^{4}$ online digital media stores (e.g., iTunes, Amazon), ${ }^{5}$ and subscription-based streaming music services (e.g., Naxos Music Library, DRAM $)^{6}$ have all contributed to this heightened expectation.

These regional differences may be due to the relative clarity of American and European copyright laws, to clear policy statements by their professional organizations, or to the advantage of having past projects on which to build. The U.S.-based Music Library Association (MLA) offers an example of a clear policy statement: "the Music Library Association supports the creation and transmission of digital audio file copies of copyrighted recordings of musical works for course reserves purposes."7 Many American institutions benefit from this and model their own local policies on those of MLA. ${ }^{8}$ Further, there is a regional tradition for American librarians to draw from, with digital music library and electronic reserves projects dating back at least a decade. ${ }^{9}$

Canadian librarians are less fortunate in this respect. There is no analogous policy statement from a Canadian professional organization, nor is there a comparable tradition. When these shortcomings are combined with the challenges of applying complex copyright legislation to rapidly evolving technologies, it is not surprising that few Canadian music libraries provide streaming access to sound recordings. As Micheal Geist, law professor at the University of Ottawa and Canada Research Chair in Internet and E-commerce Law, says of Canadian copyright, "If Canadians are to respect the law, they must first understand it." 10 Outside of the academic environment there have been some notable examples of successful streaming audio 
projects. Canadian Broadcasting Corporation (CBC) Radio 2, for example, hosts its Concerts on Demand service, ${ }^{11}$ which contains over 850 concerts recorded by the CBC. Another is CentreStreams, ${ }^{12}$ which is hosted by the Canadian Music Centre and offers thousands of archival recordings by Canadian composers.

Given this context, our main goal is to describe two projects that provide expanded access to library collections: a digital archive of Faculty of Music recordings at the University of Toronto, and an electronic course reserves pilot project at Concordia University. By looking at these two projects, we will address issues of access, technology, metadata, workflow, and copyright. This information will be of interest to librarians who are considering similar projects; these case studies provide an indication of the resources required and detail two unique approaches to implementing streaming audio technologies. To begin, we will look more closely at our survey of Canadian music librarians.

\section{SURVEY OF CANADIAN MUSIC LIBRARIANS}

The survey, based on one administered to Iowa academic librarians, ${ }^{13}$ was sent to the CANMUS-L listserv, "the electronic mail distribution list for [the] Canadian Association of Music Libraries, Archives, and Documentation Centres, ${ }^{14}$ in both English and French, in August 2009. We received 30 responses from a pool of 238 listserv subscribers. For the most part, listserv members work with one of the seventy-one music collections ${ }^{15}$ in Canada.

When asked ". . . are you currently offering a streaming audio service (e.g., to deliver faculty or student recordings, course reserves, etc., online) at your institution?", a large majority (22 respondents) indicated they were not (Figure 1). To the follow-up question "If not, why not?", respondents suggested that lack of time and financial resources were significant issues 
(Figure 2). Concerns about copyright, however, were singled out as the major factor in the comments section. To the question "Do you have plans to offer a streaming service in the future?", respondents were non-committal; 14 said "maybe" and 11 gave no answer at all (Figure 3).

FIGURE 1. Survey responses to the question "Are you currently offering a streaming service?"

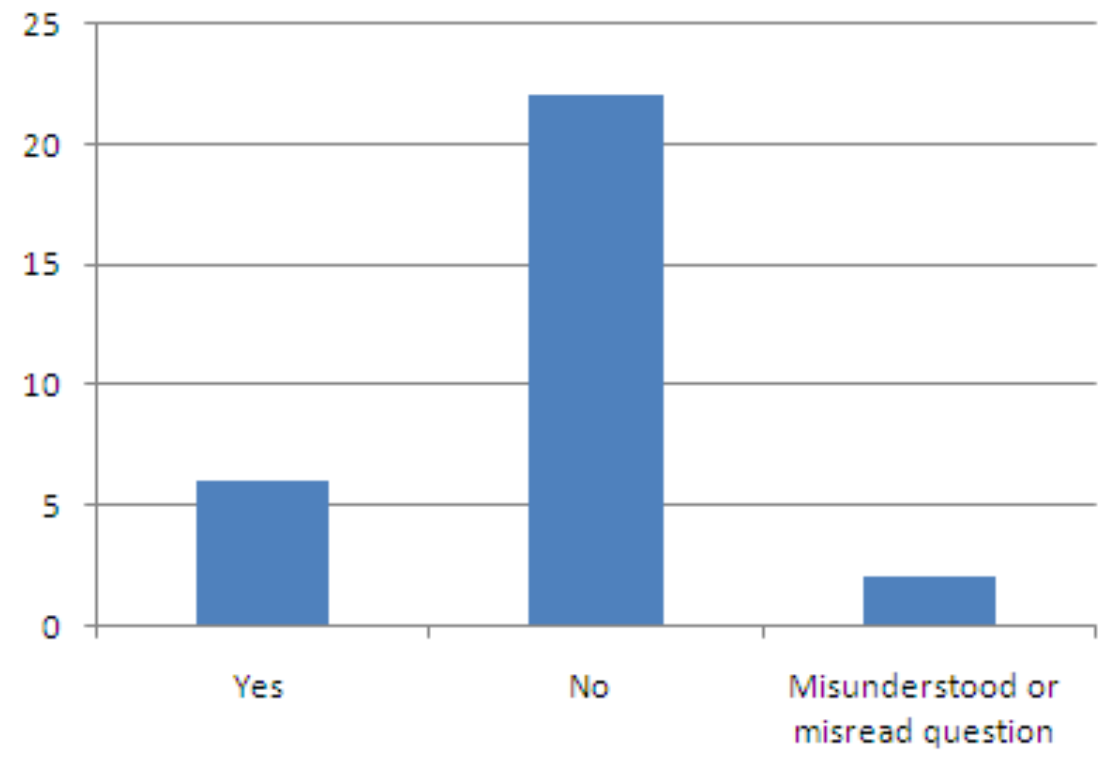

FIGURE 2. Survey responses to the question "If not, why not?" 


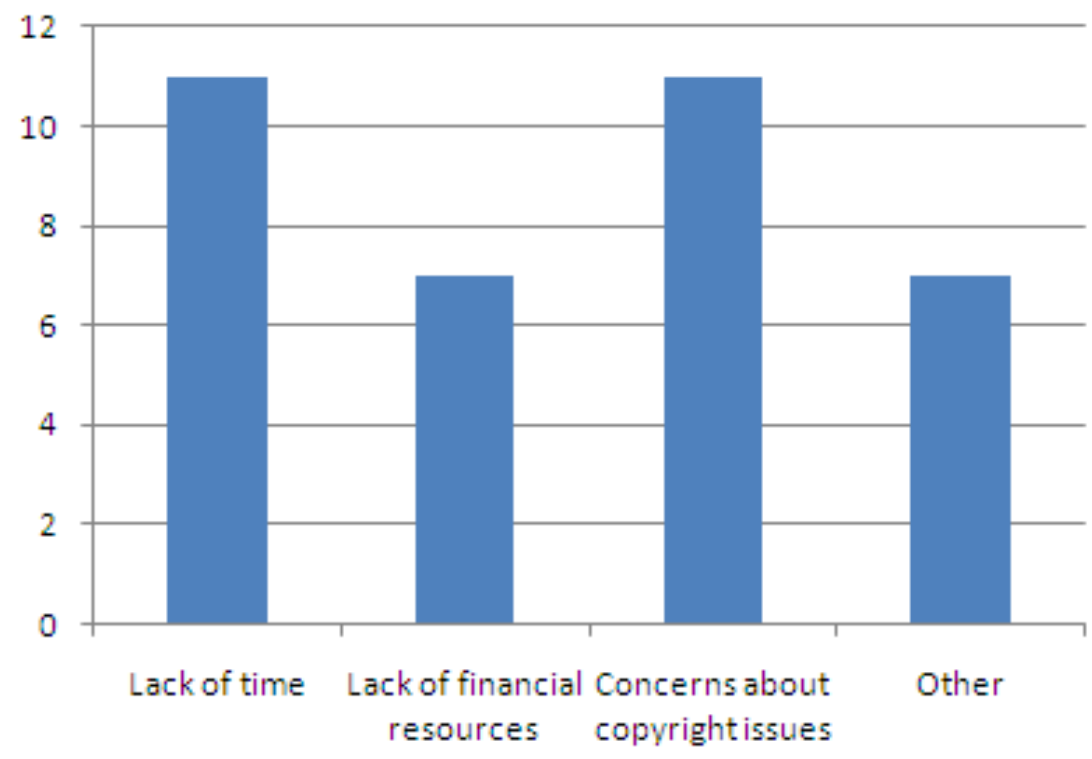

FIGURE 3. Survey responses to the question "Do you have plans to offer a streaming service in the future?"

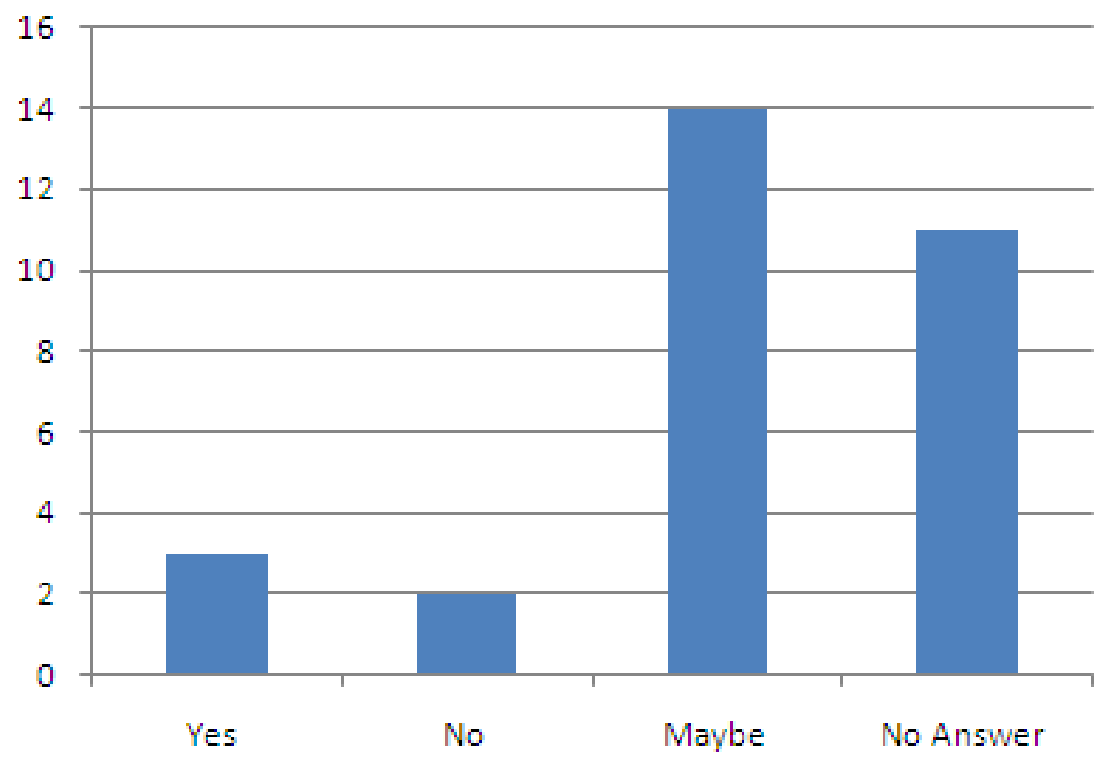

The results of our survey indicate that streaming services are of interest to many institutions. This was clear from respondents' formal comments in the survey as well as from informal feedback received at presentations we gave at national and regional conferences. 
Despite the obvious interest, our survey shows that few Canadian institutions are offering these types of services, apart from subscription databases such as Naxos Music Library and DRAM. The perceptions that resource requirements are prohibitive, and that the legal issues surrounding copyright are too difficult to navigate, seem to be preventing streaming initiatives at this time. We present these two projects, then, to demonstrate that the resource requirements do not need to be onerous, that copyright law can be successfully navigated, and that the benefits are appreciated by the students and faculty who access our collections.

\section{BACKGROUND AND OBJECTIVES}

At the University of Toronto, the Music Library collects recordings of events hosted by the Faculty of Music, ranging from lectures to gala concerts. This archival collection dates back forty years and currently, over 100 recordings per year are added, representing valuable intellectual content and institutional cultural memory. There are many examples of unique recordings that cannot be found elsewhere, including pieces written by student composers as well as by composers with more established careers.

Due to the unique content and cultural memory represented in the archival recordings, the need for the preservation of this content is important. Historically, the recordings have existed in various formats including reel-to-reel, cassette, and compact disc. These physical formats have a finite life span and exist in a continual state of decay. The knowledge of how to use and repair equipment is also becoming scarcer. Digitizing the collection allows for the collocation of various formats which will standardize equipment needs and expertise. Furthermore, any collocation of formats will aid in the process of migrating the collection into the future anticipating potential technologies and preparing the collection for an unknown future 
environment. Streaming the resources after they have been digitized offers the most effective way to provide access and preserve the collection. Finally, an additional benefit of digitization is the standardization of metadata which can translate into better and more dynamic search interfaces.

In summary, the primary goal of digitizing and streaming our collection is to improve the access, retrieval, and delivery of the collection. An additional goal of this project is to position the collection in a manner that is conducive for migration when the need arises, and preserving the content for the future. Now that the recordings in the Faculty of Music's Events database at the University of Toronto are in a digitized format, they can be migrated to other formats much more easily as technologies change.

Concordia University Libraries provide music students with access to sound recordings for course-related listening. Typically this happens by placing compact discs on short-term loan (course reserve). Music students borrow the compact discs and then listen to them in the library or elsewhere. While successful in the past, this approach is now outdated in a context where students are increasingly accustomed to online access. In an attempt to improve access to music for course-related listening, Concordia has launched a streaming audio pilot project. ${ }^{16}$

This pilot project allows students remote access to selected sound recordings through the library website. The pilot project is intended to fill in gaps in the collection not covered by our subscription databases (e.g., Naxos Music Library) and is limited, through authentication, to students of a particular course. More specifically, the goals of the streaming audio pilot project are threefold: to improve access to sound recordings; to keep the library relevant to students; and to help ensure that students listen to the correct version of a given work. The access limitations of the traditional (i.e., compact-disc based) course reserve system are numerous. To listen to the 
discs, students are required to make a trip to the library during library hours where they will have one-at-a-time access for a short period. The streaming audio service, by contrast, provides remote, around-the-clock, simultaneous access.

Likely as a consequence of these limitations, Concordia faculty members report that many students are bypassing the library entirely for course-related listening; instead, they have been looking for the music online. Interestingly, faculty members also report that these students frequently have trouble locating the correct versions of musical works. They may find a particular work online, but often it is not the specific version, performance, or recording intended for their course. Two related goals for the streaming service, then, are to keep the library relevant to students by providing convenient access to the proper version of a musical work.

\section{SOFTWARE USED}

The process involved in streaming the Faculty of Music's Events collection includes ripping and encoding digital CDs in order to host them in an appropriate format on our server. Also, content that is not already in a digital format (such as an audio cassette or reel-to-reel tape) needs to be digitized. Software required to accomplish this can vary drastically based on the scope of the project, the requirements of the institution, and, not least of all, available financial resources. At the University of Toronto's Music Library, the software requirements needed to digitize and stream the Events collection were modest, and it was decided that open source and freeware software would be the most appropriate. We required the following:

- Software to encode CDs

- Software to digitize analog formats

- Software to create XML-based playlist 
- A database to record metadata

- Flash software

For encoding software, we opted to go with Exact Audio Copy (EAC) ${ }^{17}$ which is freely available, open source software used for ripping and encoding CDs (Figure 4). EAC is able to rip damaged CDs and attempts to create the best-quality copy possible. EAC is also able to encode to the WAV file type, which we chose for the preservation copies (the format was widely used, uncompressed, and easy to convert), and MP3 for the streaming copy (as the file size is small, they are easy to stream and well supported). Other features of the software were also quite useful for our purposes. For example, it allowed for file-naming practices to be automated; the software will automatically name the files according to a set of parameters established at the beginning, and will also place them in the folder and drive specified by the user. In addition, EAC allows for automatic conversion to a wide variety of formats. It will, therefore, rip a CD to the WAV format for archival purposes as well as convert the WAV to an MP3, which we use for streaming files.

FIGURE 4. Screenshot of Exact Audio Copy (EAC) ripping a CD. 


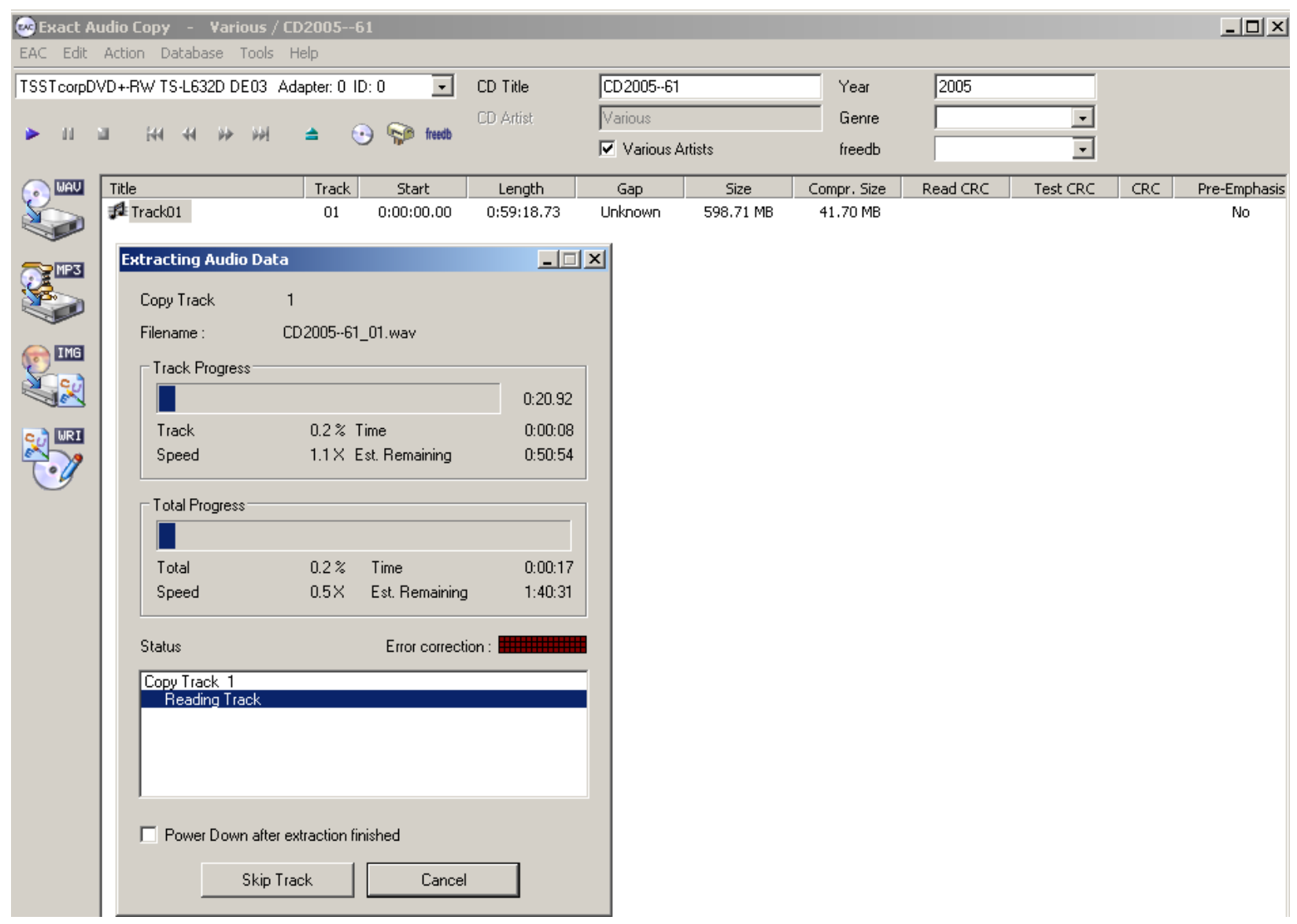

For digitizing analog formats like reel-to-reel tape and cassette, we use Audacity ${ }^{18}$ (Figure 5). Similar to EAC, Audacity is freely available, open source software with a large community of support and involvement. Audacity supports a wide variety of formats and is able to create WAV and MP3 files. Audacity is a full-featured Digital Audio Workstation (DAW), allowing for advanced editing options as well as the ability to add effects (Compressor, Amplify, and Normalize are useful examples). The sound quality is excellent and supports recording and editing 16-bit, 24-bit, and 32-bit (floating point) samples, up to a $96 \mathrm{kHz}$ sample rate.

FIGURE 5. Screenshot of Audacity digitizing an analog source. 


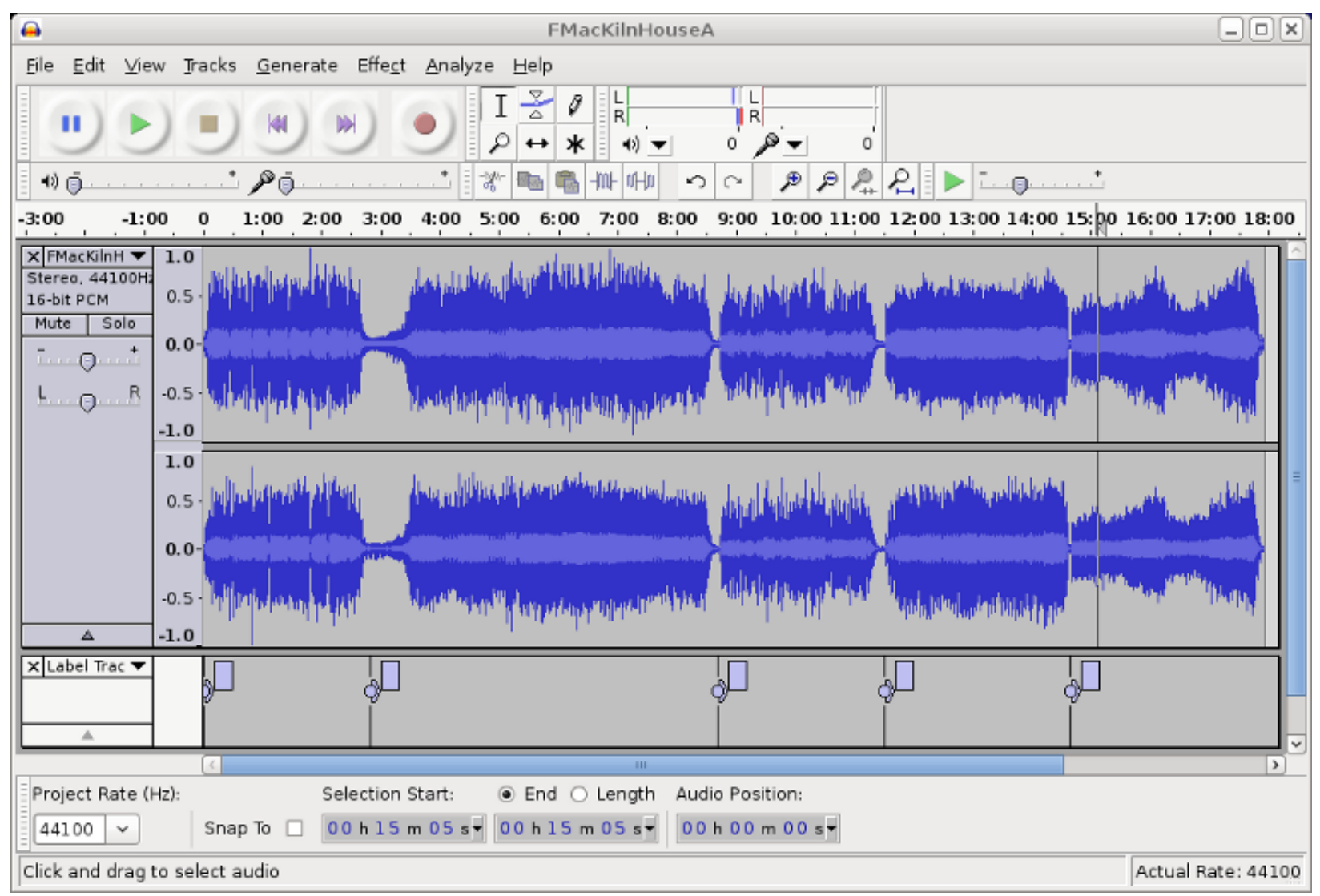

To create XML-based playlist files, which are used by the Flash media player to link to tracks stored on the server, we use Notepad,$++{ }^{19}$ but any number of text editing applications would work just as well. XML highlighting is supported, which is useful. The Flash player we used was the JW FLV Player, ${ }^{20}$ which is freely available to non-profit educational institutions (Figure 6).

FIGURE 6. Screenshot of the Flash player embedded within the search results of the database. 


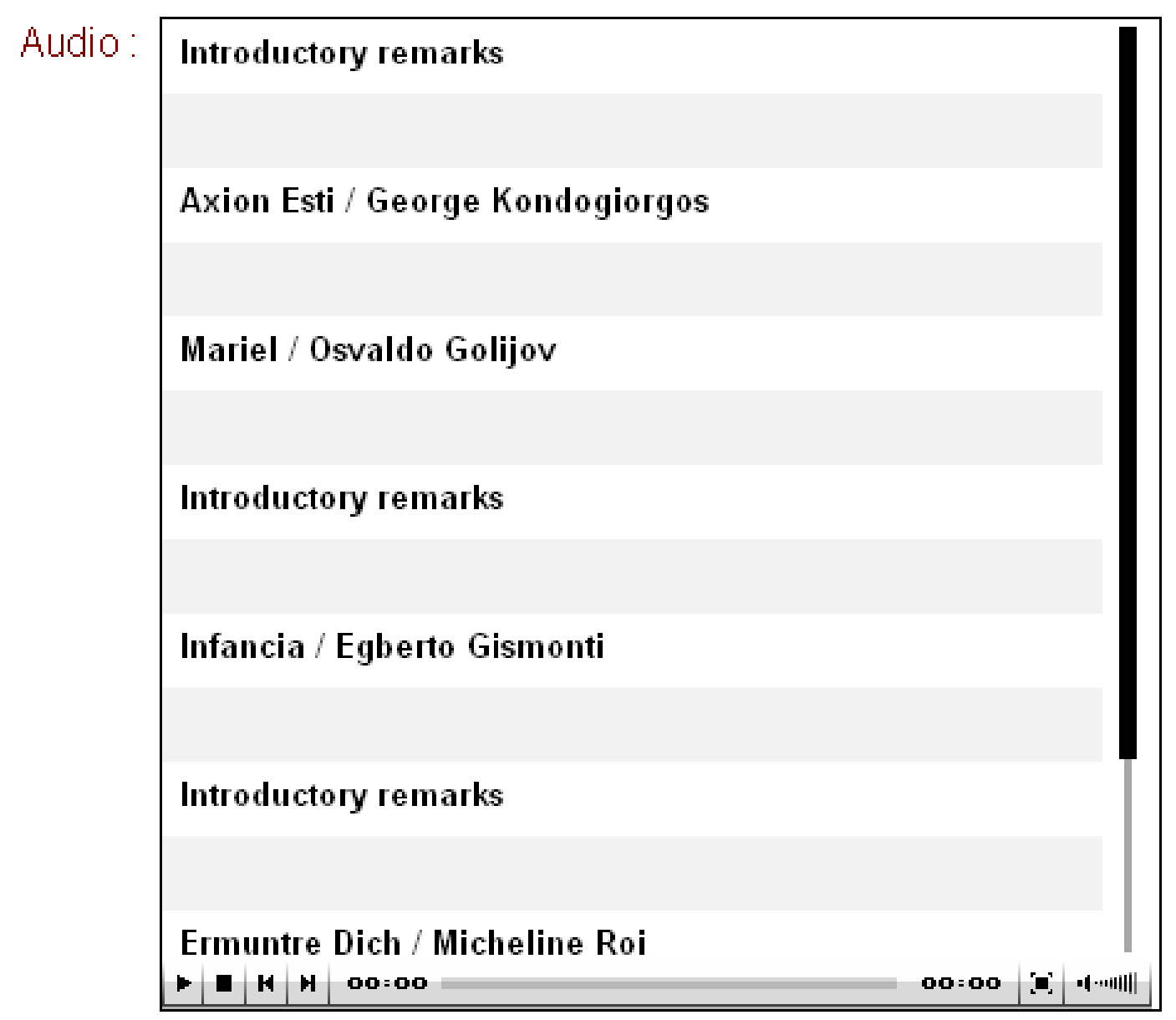

The database we use is DB/TextWorks with Web Publisher Pro. ${ }^{21}$ DB/TextWorks is an effective tool for the storage, creation, and access of metadata, while Web Publisher Pro provides access to the database via the web. Some features that are important in DB/TextWorks include its ability to allow for embedding HTML code and the control over the HTML and CSS files that display the content; this allows for the personalization of presentation as well as for control over content delivery. One important way in which we personalize the HTML code is by using the HTML <embed> code to "embed" a media player inside the database record. Another feature of DB/TextWorks that we found desirable is that the records in DB/TextWorks are stored as XML files. This is attractive as XML is not a proprietary format and is, of course, quite 
extensible; therefore the XML format allows us to maintain control over the data, while giving us the flexibility to migrate it in the future, perhaps to other platforms or formats.

There are some drawbacks to Web Publisher Pro. For example, all media files must be stored and managed externally from the DB/TextWorks database (the metadata is stored in the database, but corresponding documents such as the media file and XML file are only linked to). Furthermore, Web Publisher Pro does not serve the files. The media files for the faculty Events database are stored in folders and are managed manually, and a Windows server is used to serve the files. This complicates matters slightly, as it increases management issues and therefore the possibility of errors. The issue of storing media files externally from the database is similar to what you find in standard library catalogs, where the catalog entry for an item is simply a surrogate for the physical item, directing patrons to its location in the stacks. This concept of a database entry acting as a surrogate for the media file is not necessarily the only option in a digital world; for example, Dspace, ${ }^{22}$ a digital repository software solution, stores media files internally and collocates various parts and instances of the intellectual content (e.g., metadata, playlists, and audio files).

In addition to the external storage of media files, an external media player is required. In our case we use a stand-alone Flash player which is stored on the server and linked to via the HTML <embed> code. There are other systems that address this issue more comprehensively; for example, Indiana University's open source, free, digital content management system Variations3. ${ }^{23}$ Variations 3 has its player built in and is fully integrated into the repository. Web Publisher Pro is a closed source product and requires a substantial financial investment, whereas DSpace and Variations3 are both free and open source. Closed source 
software limits the library's ability to customize features, to create add-ons, and to share features developed internally within a community, which in the case of DSpace has become quite vibrant.

The software requirements for Concordia's streaming audio project are similarly modest, and include an emphasis on open source and freeware software. Software is required for three different activities: (1) for converting the original compact discs to MP3 files (ripping); (2) for adding metadata to the files (tagging); and (3) for making the files available through the library's website (streaming).

We use Apple's iTunes to create MP3 files from compact discs. We chose iTunes primarily because of its ability to encode high-quality MP3 files, but also because it is free and easy to use. Although iTunes provides the ability to convert compact discs into higher-quality, uncompressed, audio formats (WAV or Apple Lossless), we chose to use the MP3 compressed format in order to save both server space and bandwidth.

iTunes and TagScanner ${ }^{24}$ are used to handle the creation of metadata. iTunes is used to add metadata (song, artist, composer, etc.) to the MP3s, since this information is not transferred in the conversion process. iTunes reads the compact disc, and then, using clues such as track length and track order, tries to obtain the correct metadata online from the Gracenote ${ }^{25}$ database. When a match is found, it writes the metadata to the ID3 $\operatorname{tags}^{26}$ of the MP3s as a part of the conversion process. When this process is successful, the metadata becomes an intrinsic part of the MP3 file, and no surrogate (e.g., CD liner notes) is needed.

We use TagScanner, on the other hand, for file naming. TagScanner makes it possible to batch edit file names using information pulled from the ID3 tags of the MP3s themselves. For consistency, all of our files are named with the following convention: <track number> <performing artist><track title><file extension> (e.g., "13 Frank Zappa \& The Mothers of 
Invention - Help, I'm a Rock.mp3"). Although files are named automatically by iTunes during the conversion process, we found that TagScanner offers greater control over how this is done.

Several different pieces of software are required to stream the MP3 files. First, once the MP3 files are organized into folders, we use an open source Visual Basic Script ${ }^{27}$ to create XML (eXtensible Markup Language) playlists in XSPF (XML Shareable Playlist Format). ${ }^{28}$ The playlists determine the order in which the songs will stream. Secondly, we use the JW FLV (Flash Video) Player to play the MP3 files. Finally, we use the "swfobject.js" javascript code ${ }^{29}$ to embed the JW FLV Player directly into the library web page. The streaming software, then, works together in the following way:

1. A student uses his or her web browse to visit the library's website. (The student will need to download and install the popular Adobe Flash plug-in, if they have not already done so.)

2. The web browser reads the "index.html" file.

3. The "index.html" file points to the "swfobject.js" file, causing the JW FLV Player to display on the web page.

4. The display of the JW FLV Player is determined by the "player.swf" file (which contains the Flash code for the JW FLV Player) and the "nacht.swf" file (which contains the Flash code for the skin, or appearance, of the JW FLV Player).

5. The student selects the desired playlist from a drop-down menu.

6. The JW FLV Player loads the corresponding XSPF playlist (e.g., "playlist3.xml") and displays the artists and songs available on that list. 
7. The student selects a particular track to listen to, causing the JW FLV Player to load the selected MP3 file by way of file and folder location information stored in the XSPF playlist.

For more information, please consult the "How to set up your own streaming audio web site" online guide which documents the Concordia set-up process in detail. ${ }^{30}$

FIGURE 7. Screenshot of the file and folder structure (note: folders contain the MP3 files).

\begin{tabular}{|c|c|c|c|}
\hline Name - & Size & Type & Date Modified \\
\hline G_Baroque & & File Folder & $1 / 10 / 20094: 08 \mathrm{PM}$ \\
\hline Classical & & File Folder & $2 / 4 / 20097: 47 \mathrm{PM}$ \\
\hline Contemporary & & File Folder & $1 / 10 / 20094: 04 \mathrm{PM}$ \\
\hline GarlyxxthCentury & & File Folder & $1 / 10 / 20094: 02 \mathrm{PM}$ \\
\hline Golk & & File Folder & $1 / 10 / 20093: 58 \mathrm{PM}$ \\
\hline Medieval & & File Folder & $1 / 10 / 20093: 58 \mathrm{PM}$ \\
\hline Non-Western & & File Folder & $1 / 10 / 20093: 57 \mathrm{PM}$ \\
\hline GPPostwWII & & File Folder & $1 / 10 / 20093: 56 \mathrm{PM}$ \\
\hline Genaissance & & File Folder & 1/10/2009 3:55 PM \\
\hline Romantic & & File Folder & $1 / 10 / 20093: 54 \mathrm{PM}$ \\
\hline$\sqrt{12}$ index.html & $3 \mathrm{~KB}$ & Firefox Document & $1 / 12 / 200912: 44 \mathrm{PM}$ \\
\hline 砲nacht.swf & $8 \mathrm{~KB}$ & Shockwave Flash Object & $7 / 9 / 200811: 23 \mathrm{AM}$ \\
\hline player.swf & $39 \mathrm{~KB}$ & Shockwave Flash Object & $9 / 29 / 20084: 05 \mathrm{PM}$ \\
\hline playlist $1 . x m l$ & $13 \mathrm{~KB}$ & XML Document & $1 / 10 / 20092: 38 \mathrm{PM}$ \\
\hline playlist2.xml & $30 \mathrm{~KB}$ & XML Document & $1 / 10 / 20092: 38 \mathrm{PM}$ \\
\hline playlist $3 . x \mathrm{ml}$ & $21 \mathrm{~KB}$ & XML Document & $1 / 10 / 20093: 10 \mathrm{PM}$ \\
\hline playlist4.xml & $53 \mathrm{~KB}$ & XML Document & $1 / 10 / 20093: 28 \mathrm{PM}$ \\
\hline playlist5.xml & $4 \mathrm{~KB}$ & XML Document & $1 / 10 / 20092: 39 \mathrm{PM}$ \\
\hline playlist6.xml & $8 \mathrm{~KB}$ & XML Document & $1 / 10 / 20092: 39 \mathrm{PM}$ \\
\hline playlist 7.xml & $18 \mathrm{~KB}$ & XML Document & $1 / 10 / 20092: 39 \mathrm{PM}$ \\
\hline playlist8.xml & $15 \mathrm{~KB}$ & XML Document & $1 / 10 / 20092: 40 \mathrm{PM}$ \\
\hline playlist9.xml & $4 \mathrm{~KB}$ & XML Document & $1 / 10 / 20092: 40 \mathrm{PM}$ \\
\hline playlist $10 . x \mathrm{ml}$ & $49 \mathrm{~KB}$ & XML Document & $1 / 10 / 20093: 43 \mathrm{PM}$ \\
\hline swfobject.js & $10 \mathrm{~KB}$ & JScript Script File & $9 / 29 / 2008$ 4:04 PM \\
\hline
\end{tabular}

FIGURE 8. Screenshot of the player in use. 


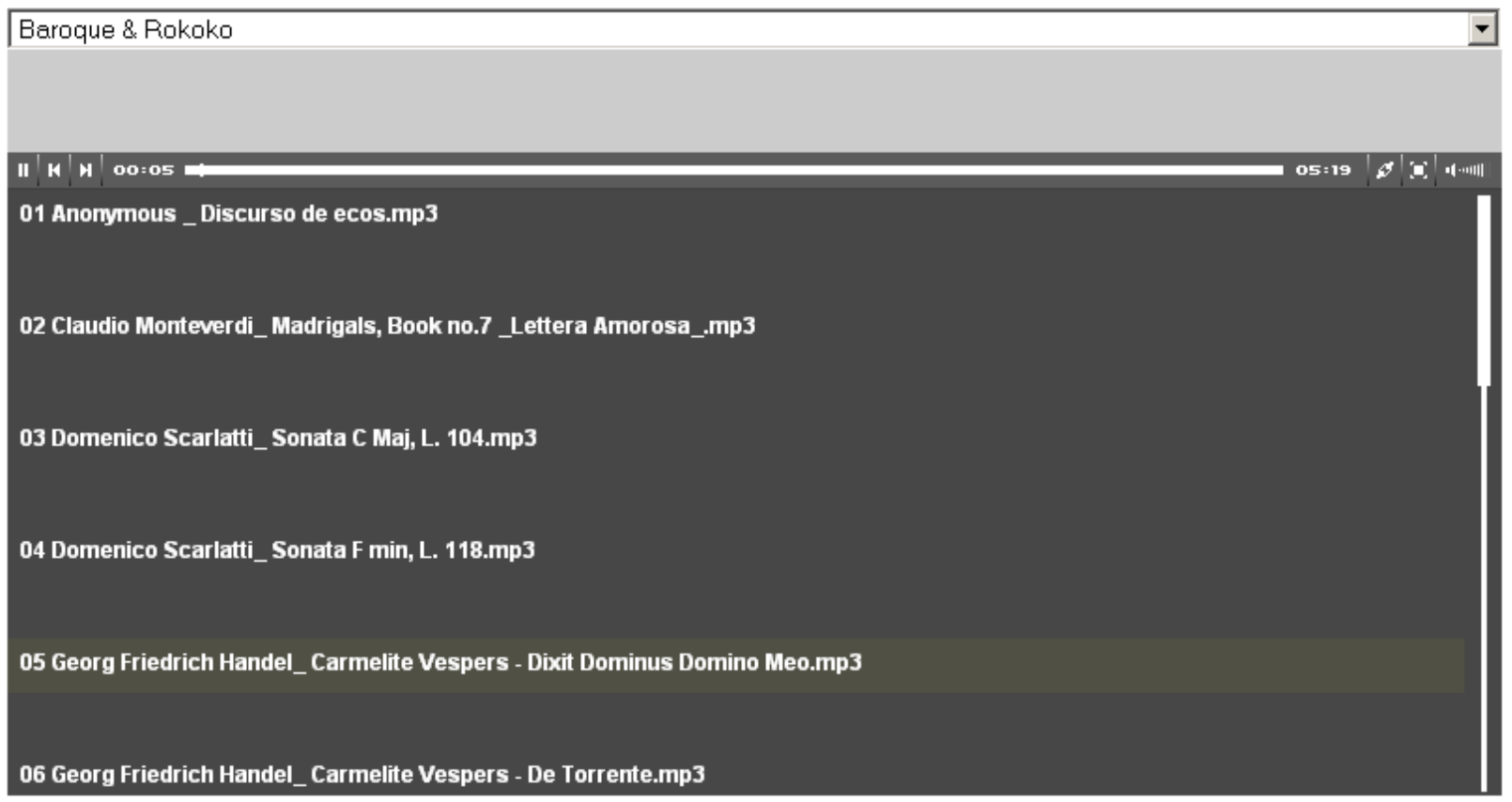

\section{HARDWARE USED}

The hardware necessary to carry out the project at University of Toronto was fairly minimal and an effort was made to use equipment already available. We used a Windows server, a virtual server, desktop computers, and playback equipment we already had, but it was necessary for us to purchase an analog-to-digital converter. The users' hardware requirements are modest as well. The library computers are sufficient, and patrons' laptops are fine. Headphones are necessary but were already owned, and therefore not an additional expense.

For the Concordia Libraries project, we were able to utilize existing hardware. All of the setup work was done on a typical staff PC running Windows XP. Now, once all of the required files are ready, they are moved to our Windows server, where they are accessed through the library website.

\section{METADATA}


Managing metadata is an important part of the project at the University of Toronto, as the database is a growing resource intended to be preserved indefinitely, and therefore consumes much of our time. The technical, structural, and descriptive metadata will determine the success of the project as the metadata will be instrumental in providing access and in migrating files for future use.

The technical metadata we record includes file type and size, the date of digitization or duplication/transfer of media data, encoding information, processing information, related dates, methodologies of creation, and any processing of the file. Technical and provenance metadata is stored and handled in several ways. Some elements are stored as part of the file itself: size, format, date modified, date created, and duration. The technical metadata recorded as part of the database record includes the method of creation, the software used to create the digital file (Audacity or EAC), and the original source (cassette, reel-to-reel, or CD).

Structural metadata documents the relationships between files and parts of an entity, such as the MP3 file for streaming, the WAV file for preserving, the PDF file for the event program, and the XML file for the playlist. Some of this metadata, as with the technical metadata (there being some overlap), is stored in a few ways. The file-naming practices we use accommodate much of this type of metadata.

FIGURE 9. Screenshot illustrating metadata and file-naming practice.

\begin{tabular}{|c|c|c|c|c|c|}
\hline - lame - & Size & Type & Date Modified & Date Created & Duration \\
\hline (1) CD2009--11_03.mp3 & $16,459 \mathrm{~KB}$ & MPEG Layer 3 Audio File & 02/03/2009 10:57 AM & $02 / 03 / 2009$ 11:32 AM & $0: 14: 02$ \\
\hline (]) CD2009--11_03.wav & $145,133 \ldots$ & Microsoft Wave Sound Format & 02/03/2009 10:10 AM & $02 / 03 / 200911: 40 \mathrm{AM}$ & \\
\hline CD2009--11_04.mp3 & $6,748 \mathrm{~KB}$ & MPEG Layer 3 Audio File & 02/03/2009 10:56 AM & $02 / 03 / 2009$ 11:32 AM & $0: 05: 45$ \\
\hline D] CD2009--11_04.wav & $59,483 \mathrm{~KB}$ & Microsoft Wave Sound Format & 02/03/2009 10:11 AM & $02 / 03 / 200911: 40 \mathrm{AM}$ & \\
\hline
\end{tabular}


The "name" column shows the file name. The "CD" portion of the name represents the fact that it is an audio file, while the next four numbers indicate the year. The numbers after the dash represent the recording number within the previously mentioned year. The last number is track, followed by file type. These files are then stored in a folder on the server. Examples of metadata stored with program files is similar and the naming convention is the same as for the audio files. The programs for the events, however, are stored as PDF files in a separate folder named "Programs."

Other aspects of structural metadata are addressed in the database record itself. The call number uniquely identifies an item and is used as a naming convention to link various parts together. A call number of CD 2004 98, for example, is associated with a WAV file named CD2004--98_01.wav and a program named CD2004--98.pdf. The database record also allows for direct linking to various "parts" of a complete item. The structural metadata recorded in the database record includes dates associated with the creation of the digital file (or migration of that digital file), the method of creating that digital file (using EAC or Audacity), and the original source of the file and its location. Descriptive metadata, such as title, performers, composers, content, and notes, are stored in the database record.

While metadata is a significant consideration for the Concordia course reserves project, it is not nearly as important a factor as it is in the University of Toronto archival project. There are two main reasons for this: (1) course reserves are transient by nature; what is required listening this semester may not be used again in the future, and (2) professors typically provide their students with extensive information about the music selected for their course. As a result, it is only necessary to make sure the tracks are properly labeled so students can easily identify them. 
As discussed earlier, iTunes is used to create the metadata that is stored in the ID3 tag of each MP3 file. When a compact disc is being converted, iTunes contacts the Gracenote database and then uses the information it finds to fill in the various missing pieces of descriptive metadata. This is an imperfect process, however, and errors frequently occur. It is always necessary, then, to verify that the automatically supplied metadata is correct. This is done by cross-checking with the listening list provided by the course instructor.

FIGURE 10. Screenshot of the metadata stored in the ID3 tag of the MP3.

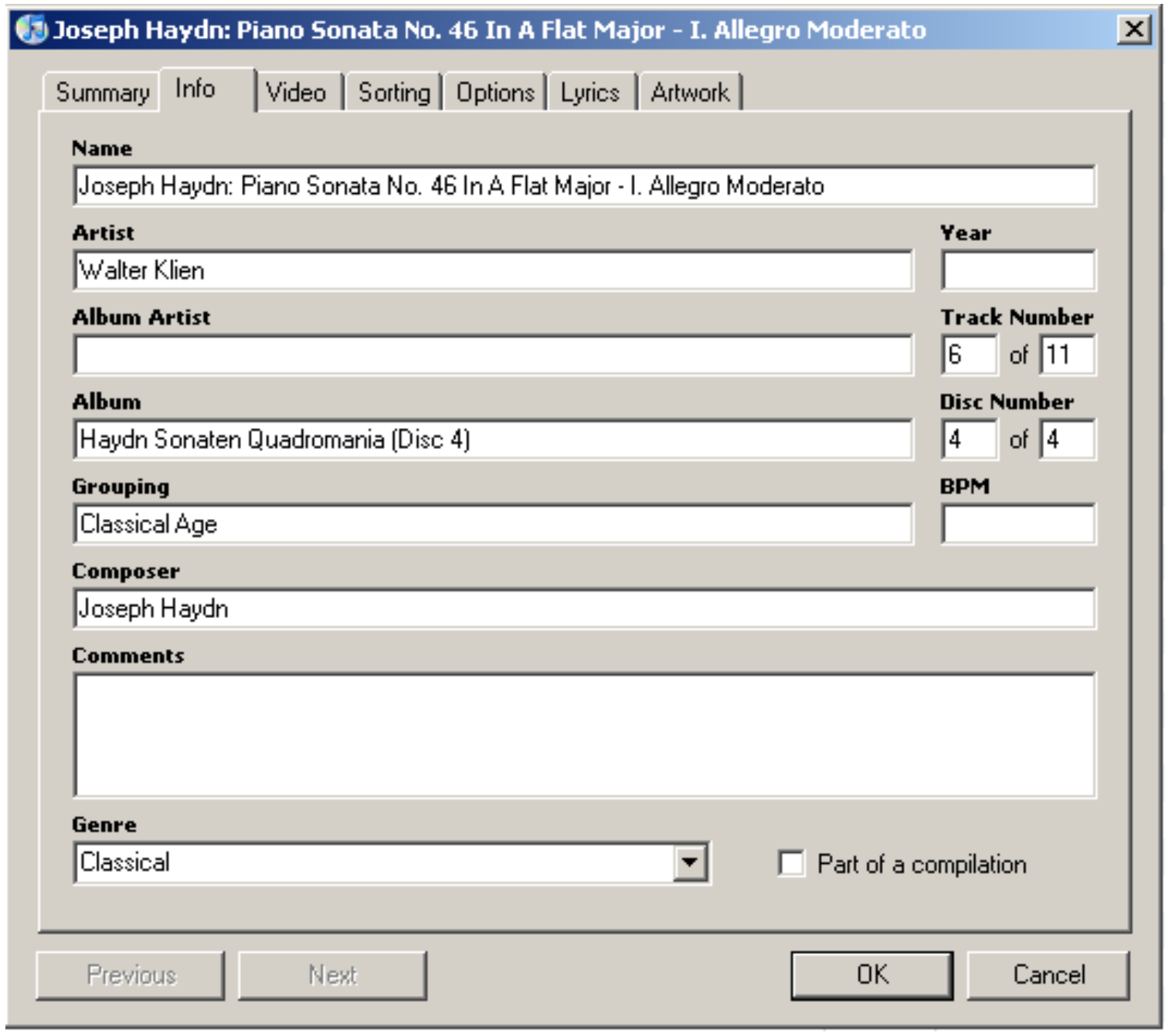




\section{WORKFLOW}

Workflow is an aspect of the project at the University of Toronto that is in development and depends on the format in which the content was originally stored. For recordings (compact discs) from 1998 to the present:

1. We rip the $\mathrm{CD}$ with $\mathrm{EAC}$, including the entry of metadata and file names. EAC encodes streaming (MP3) and archival (WAV) copies at the same time. EAC also automatically names and deposits files into pre-defined folders.

2. A database record is created using DB/TextWorks.

3. An XML playlist file is created using Notepad++.

4. The concert program is scanned and stored as a PDF file in the appropriate folder on the server.

The process differs slightly for analog formats (reel-to-reel, cassette) from 1971 to 1997. These formats require a separate, four-step process:

1. Digitize recording through an analog-to-digital converter using Audacity.

2. Manually name files (EAC does this automatically for digital formats while ripping them).

3. Make a streaming copy.

4. Export and transfer the files to appropriate folders.

Metadata for older recordings is often insufficient or lacking altogether, and unfortunately, is left as is (one track per side, for example). For data that is available, workflow is as follows:

1. Information is recorded in the DB/TextWorks database record.

2. Information is added to the playlist. 
3. The program is scanned.

Digitizing content takes the majority of our time. The CDs can be ripped fairly quickly, and the metadata can be entered and XML playlists created while ripping is taking place. Scanning the event program adds a few minutes to the process. Analog formats take longer as they are digitized in "real time"; for example, an hour concert takes an hour to digitize. Difficulties with the quality of metadata (mislabeled tracks, for example) can prove to be problematic and time consuming.

Given the pilot project status of the Concordia project, the workflow will continue to change as the project evolves. The bulk of the work is currently handled by one staff member. As the project expands, however, it may be necessary to involve more people. For now, we follow an eight-step process:

1. The compact discs are converted into MP3s using iTunes.

2. Metadata is added to the MP3s using iTunes via Gracenote.

3. Metadata is verified using the professor's listening list.

4. The MP3s are moved to folders, and listed in the order in which they should play.

5. File names are standardized using TagScanner.

6. XSPF playlists are created using Visual Basic Script.

7. All of the files are put in one folder and are then moved onto the server.

8. A new record is created in the course reserves module of the Integrated Library System (ILS) and appropriate security settings are put in place.

Creating the MP3s, and then adding and verifying the metadata (steps 1-5) consumes approximately $80 \%$ of the time. The remaining steps typically go quickly. As a rough estimate, it takes about 3.5 hours from start to finish to set-up a six-CD course reserve web page. More 
time will be required for CDs that contain a large number of tracks (compilations that contain numerous short excerpts, for example). The main variable is the quality of the metadata imported from Gracenote. When poor-quality metadata is imported (spelling mistakes, incorrect information, etc.), the set-up time can take much longer.

\section{RIGHTS MANAGEMENT}

To protect the intellectual content preserved in the Faculty of Music Events collection at the University of Toronto, streaming is limited to a range of specific IP addresses. In order to access the Flash player portion of the search results page displayed on the web, the user's IP address must be recognized as belonging to the Faculty of Music at the University of Toronto; therefore, only computers on the Faculty of Music campus can access the streaming files. Offsite use of the database retrieves the metadata only. Furthermore, the audio files are streamed as MP3s and are therefore only accessible in a deprecated format. The download features associated with Flash players are disabled as well.

At Concordia we met with our internal legal counsel to discuss the relevant copyright issues. In order to access the streaming audio files for a particular course, Concordia students must authenticate twice: first as members of the Concordia community (by entering their name, barcode number, and library PIN), and then as students enrolled in the course (by entering a course password). Students must also agree, at the point of authentication, to the terms and conditions of both the Canadian Copyright Act and Concordia's Policy on Copyright Compliance. We take additional precautions to prevent students from downloading the files while allowing streaming access from both on and off campus. 


\section{STUDENT AND FACULTY REACTION}

At the University of Toronto no formal approach to soliciting input or comments on the streaming process has taken place yet. Informally, however, the demonstrations of the project have elicited responses of excitement and approval.

Thus far, the reaction from Concordia students and faculty has been extremely positive. A small, informal survey administered in April 2009 provides some indication that both students and faculty are happy with the service. One music professor, for example, remarked, "I am deeply appreciative and thankful for your service in setting this up. This will prove to be invaluable." These positive responses are consistent with surveys done in American academic institutions. For example, according to a survey done at the University of North Carolina, 90\% of students prefer online listening. ${ }^{31}$ At Indiana University, reports show that students who used the digital course reserves "were listening to far more titles than they had using traditional formats." 32

\section{FUTURE DEVELOPMENTS}

Looking towards the future of the Faculty of Music Events database at the University of Toronto, exploration of grants or other funding options is a priority. Work-study students or those doing a practicum could drastically reduce the time required to complete this project. In addition to funding and work-study options, partnerships with other institutions or with other departments within our own institution can and should be explored. Integrating other departments into the workflow could also aid substantially. Partnerships could include equipment, staff, or other resource sharing. Procedures will need to be continually re-evaluated to ensure that they are as efficient as possible. For example, communicating our needs more 
effectively to the recording engeneers could result in digital copies being deposited directly onto our server without the need to rip CDs. Also, properly annotated event programs (e.g., tracks being clearly identified) could aid in the collection of metadata.

At Concordia Libraries, we are hoping to eventually move from the pilot project phase to a full-fledged service. In order to do this, we will need to purchase new equipment (e.g., a dedicated streaming server) and to involve at least one other staff member in the set-up process. Documenting positive feedback from both faculty and students will likely play a role in securing the necessary funding. We are also interested in developing a mobile version of the service, so students can access sound recordings for course listening through mobile devices like the Blackberry, iPhone, and iPod Touch.

\section{CONCLUSION}

Apart from subscription databases, providing online or streaming access to digitized sound recording collections is currently in a very early stage of development in Canadian academic libraries. Concerns about copyright and lack of time have been cited as the top reasons. The upcoming overhaul of the Canadian Copyright Act will likely have a significant impact on Canadian libraries, especially with regards to the digital delivery of information.

We have developed and described two streaming audio systems that illustrate some of the access, technology, metadata, copyright, and workflow issues involved in improving users' access to sound recordings. Through these two projects, we have illustrated a spectrum of use for streaming audio technologies ranging from projects with more immediate and practical concerns, such as electronic course reserves, to those with longer-term objectives requiring more technical resources, such as digital preservation initiatives. We have illustrated that a range of 
projects could benefit from digitization and streaming, while being copyright compliant and without requiring a large resource commitment.

\section{NOTES}

1. Richard Griscom, "Distant Music: Delivering Audio over the Internet," Notes 59, no. 3 (March 2003): 522; Scott Phinney, “Can’t I Just Listen to That Online? Evaluating Electronic Access to Audio for Music Libraries," Music Reference Services Quarterly 9, no. 2 (December 2006): 3 .

2. Peter Findlay, "End Users, Metadata and Copyright - Who Mentioned Digitisation?" IASA Journal 29 (July 2007): 41-46; Elspath Hyams, "Breaking Barriers to Safeguard Sound in the British Library Archive," Library \& Information Update 6, nos. 1-2 (January-February 2007): 26-29; British Library, "Archival Sound Recordings," http://sounds.bl.uk/ (accessed December 8, 2009). From the home page: "If you are in a licensed UK higher or further education institution you can ... [1]isten to the recordings and download them."

3. Michiel Laan and Thomas Op de Coul, "CDR: A Music Library on the Internet," IASA Journal 31 (July 2008): 59-62; Centrale Discotheek Rotterdam, “MuziekWeb," http://www.muziekweb.nl/ (accessed December 8, 2009).

4. Facebook, http://www.facebook.com (accessed December 10, 2009); MySpace, http://www.myspace.com (accessed December 10, 2009); Last.fm, http://www.last.fm (accessed December 10, 2009).

5. iTunes, http://www.apple.com/itunes (accessed December 10, 2009); Amazon.com, http://www.amazon.com (accessed December 10, 2009). 
6. Naxos Music Library, http://www.naxosmusiclibrary.com/home.asp (accessed December 10, 2009); DRAM, http://www.dramonline.org (accessed December 10, 2009).

7. Music Library Association (MLA), "Statement on the Digital Transmission of Electronic Reserves," http://www.musiclibraryassoc.org/copyright/Resources/DigitalReserves (accessed October 15, 2009).

8. Elizabeth J. Cox, "Music Across Campus: A Study of Streaming Technology Use in Iowa Academic Libraries," Music Reference Services Quarterly 9, no. 4 (July 2007): 28.

9. For example, Dunn and Mayer wrote about Indiana University's VARIATIONS digital music library project back in 1999. Jon W. Dunn and Constance A. Mayer, "VARIATIONS: A Digital Music Library System at Indiana University," in DL '99: Proceedings of the Fourth ACM Conference on Digital Libraries, 12-19 (New York: Association for Computing Machinery, 1999), http://www.dlib.indiana.edu/variations/VARIATIONS-DL99.pdf (accessed December 10, 2009). Also, Bayne and Hodge discussed digital audio reserves in 2001; Pauline S. Bayne and Chris Hodge, "Digital Audio Reserves: A Collaborative Project at the University of Tennessee," Journal of Interlibrary Loan, Document Delivery \& Information Supply 11, no. 4 (November 2001): 25-36.

10. Michael Geist, “A Copyright Law That's Built to Last,” The Mark, http://www.themarknews.com/articles/442-a-copyright-law-thats-built-to-last (accessed October 15 2009).

11. CBC Radio 2, "Concerts on Demand," Canadian Broadcasting Corporation (CBC), http://www.cbc.ca/radio2/cod (accessed December 11, 2009).

12. Canadian Music Centre (CMC), "CentreStreams," http://www.musiccentre.ca/home.cfm (accessed December 11, 2009). 
13. Cox, "Music Across Campus," 36.

14. Canadian Association of Music Libraries, Archives, and Documentation Centres (CAML), “CANMUS-L," http://www.yorku.ca/caml/en/canmus.htm (accessed December 11, 2009). From the site: "CANMUS-L is the electronic mail distribution list for CAML, implemented to strengthen cooperation between libraries by sharing information about music, to cooperate with national and international organizations concerned with all aspects of music, and to encourage communication within the Canadian musical community."

15. Carol Ohlers, "Directory of Music Collections in Canada," http://www.yorku.ca/caml/dmcc/dmcc.asp (accessed December 11, 2009).

16. Concordia University's Streaming Audio Pilot Project team: Dubravka Kapa, Tomasz Neugebauer, and Jared Wiercinski.

17. Exact Audio Copy (EAC), http://www.exactaudiocopy.de/en/index.php/overview/basic-technology/extraction-technology (accessed December 11, 2009).

18. Audacity, http://audacity.sourceforge.net/about/features (accessed December 11, 2009).

19. Notepad++, http://notepad-plus.sourceforge.net/uk/site.htm (accessed December 11, 2009).

20. LongTail Video, "JW Player: Flash Video Player," http://www.longtailvideo.com/players/jw-flv-player (accessed December 11, 2009).

21. Inmagic, "DB/Text Web Publisher Pro," http://www.inmagic.com/products/LibrarySuite/index.html (accessed December 11, 2009).

22. DSpace, http://www.dspace.org (accessed December 11, 2009). 
23. Indiana University Digital Library Program, "Variations 3: An Integrated Digital Library and Learning System for the Music Community," Indiana University, http://www.dlib.indiana.edu/projects/variations3 (accessed December 11, 2009).

24. TagScanner, http://www.xdlab.ru/en/ (accessed December 14, 2009).

25. Gracenote, http://www.gracenote.com (accessed December 14, 2009).

26. “ID3,” Wikipedia, http://en.wikipedia.org/wiki/ID3 (accessed December 14, 2009).

27. Charlie Craig, "Create XSPF Playlists Using ID3 Tags,"

http://www.iol.ie/ craigcharlie/blog/index.html (accessed December 14, 2009).

28. The XIPH Open Source Community, "XSPF," http://www.xspf.org (accessed December 14, 2009).

29. LongTail Video, "SWFObject,"

http://www.longtailvideo.com/support/tutorials/Embedding-Flash (accessed December 14, 2009).

30. Jared Wiercinski, "How to Set Up Your Own Streaming Audio Web Site," Concordia University Libraries, http://library.concordia.ca/research/subjects/music/streaminghowto (accessed December 14, 2009).

31. Phinney, “Can’t I Just Listen to That Online?” 25.

32. Griscom, "Distant Music," 528.

\section{BIBLIOGRAPHY}

Bayne, Pauline S., and Chris Hodge. "Digital Audio Reserves: A Collaborative Project at the University of Tennessee." Journal of Interlibrary Loan, Document Delivery \& Information Supply 11, no. 4 (November 2001): 25-36. 
Cox, Elizabeth J. "Music Across Campus: A Study of Streaming Technology Use in Iowa Academic Libraries." Music Reference Services Quarterly 9, no. 4 (July 2007): 25-41.

Dunn, Jon W., and Constance A. Mayer. "VARIATIONS: A Digital Music Library System at Indiana University." In DL '99: Proceedings of the Fourth ACM Conference on Digital Libraries, 12-19. New York: Association for Computing Machinery, 1999. http://www.dlib.indiana.edu/variations/VARIATIONS-DL99.pdf (accessed December 10, 2009).

Findlay, Peter. "End Users, Metadata and Copyright - Who Mentioned Digitisation?" IASA Journal 29 (July 2007): 41-46.

Geist, Michael. "A Copyright Law That's Built to Last." The Mark, http://www.themarknews.com/articles/442-a-copyright-law-thats-built-to-last (accessed October 15 2009).

Griscom, Richard. “Distant Music: Delivering Audio over the Internet.” Notes 59, no. 3 (March 2003): 521-41.

Hyams, Elspath. "Breaking Barriers to Safeguard Sound in the British Library Archive." Library \& Information Update 6, nos. 1-2 (January-February 2007): 26-29.

Laan, Michiel, and Thomas Op de Coul. "CDR: A Music Library on the Internet." IASA Journal 31 (July 2008): 59-62.

Music Library Association (MLA). "Statement on the Digital Transmission of Electronic Reserves.” $\quad$ http://www.musiclibraryassoc.org/copyright/Resources/DigitalReserves (accessed October 15, 2009).

Phinney, Scott. "Can't I Just Listen to That Online? Evaluating Electronic Access to Audio for Music Libraries.” Music Reference Services Quarterly 9, no. 2 (December 2006): 1-29. 
APPENDIX

STREAMING AUDIO SERVICES IN CANADIAN ACADEMIC LIBRARIES

Summary of Responses

1. Excluding subscription databases such as Naxos Music Library, DRAM, etc., are you currently offering a streaming audio service (e.g., to deliver faculty or student recordings, course reserves, etc. online) at your institution?

\begin{tabular}{|c|c|c|}
\hline Answer & Response Count & $\begin{array}{c}\text { Response Percent } \\
\text { (i.e., Response Count / 30) }\end{array}$ \\
\hline Yes & 6 & $20 \%$ \\
\hline No & 22 & $73.3 \%$ \\
\hline $\begin{array}{c}\text { Misunderstood or misread } \\
\text { question }\end{array}$ & 2 & $6.6 \%$ \\
\hline
\end{tabular}

2. If no to question one, can you explain why not?

\begin{tabular}{|c|c|c|}
\hline Answer & $\begin{array}{c}\text { Response Count } \\
\text { (note: it was possible to list } \\
\text { multiple reasons) }\end{array}$ & $\begin{array}{c}\text { Response Percent } \\
\text { (i.e., Response Count / 36) }\end{array}$ \\
\hline Lack of time & 11 & $30.55 \%$ \\
\hline Lack of financial resources & 7 & $19.44 \%$ \\
\hline Lack of human resources & 1 & $2.7 \%$ \\
\hline $\begin{array}{c}\text { Concerns about } \\
\text { technology issues }\end{array}$ & 2 & $5.5 \%$ \\
\hline $\begin{array}{c}\text { Concerns about } \\
\text { copyright issues }\end{array}$ & 11 & $30.55 \%$ \\
\hline $\begin{array}{c}\text { No perceived need / } \\
\text { low priority }\end{array}$ & 3 & $8.3 \%$ \\
\hline $\begin{array}{c}\text { Not aware of the possibility to } \\
\text { stream sound recordings }\end{array}$ & 1 & $2.7 \&$ \\
\hline
\end{tabular}


3. If no to question one, do you have plans to offer a streaming service in the future?

\begin{tabular}{|c|c|c|}
\hline Answer & Response Count & $\begin{array}{c}\text { Response Percent } \\
\text { (i.e., Response Count / 30) }\end{array}$ \\
\hline Yes & 3 & $10 \%$ \\
\hline No & 2 & $6.6 \%$ \\
\hline Maybe & 14 & $46.6 \%$ \\
\hline No Answer & 11 & $36.6 \%$ \\
\hline
\end{tabular}

4. If yes to question one, please specify the type of content you are streaming.

\begin{tabular}{|c|c|}
\hline Answer & $\begin{array}{c}\text { Response Count } \\
\text { (i.e., of who answer "Yes" } \\
\text { to Question 1) }\end{array}$ \\
\hline Course reserves & 1 \\
\hline Concert events & 1 \\
\hline Skipped question & 4 \\
\hline
\end{tabular}

5. If yes to question one, briefly describe the hardware and software you use for streaming.

\begin{tabular}{|c|c|}
\hline Answer & Response Count \\
\hline Windows server, typical staff PC, Flash player & 2 \\
\hline Skipped question & 4 \\
\hline
\end{tabular}

6. If yes to question one, how have you funded the additional hardware, software, and personnel for streaming?

\begin{tabular}{|c|c|}
\hline Answer & Response Count \\
\hline Tasks absorbed by current staff or resources & 3 \\
\hline Skipped question & 3 \\
\hline
\end{tabular}


7. If yes to question one, how do you limit access to streaming audio files? (Please check all that apply.)

\begin{tabular}{|c|c|}
\hline Answer & Response Count \\
\hline On campus access & 2 \\
\hline Off campus access through proxy server & 1 \\
\hline Password protected for college/university person & 1 \\
\hline Password protected for class members only & \multicolumn{1}{|}{} \\
\hline
\end{tabular}

8. If yes to question one, where do users access streaming audio files? (Please check all that apply.)

\begin{tabular}{|c|c|}
\hline Answer & Response Count \\
\hline Library's online catalog & 2 \\
\hline Library's web site & 1 \\
\hline
\end{tabular}

9. If yes to question one, can users download these streaming files?

\begin{tabular}{|c|c|}
\hline Answer & Response Count \\
\hline Yes & 0 \\
\hline No & 3 \\
\hline Skipped question & 3 \\
\hline
\end{tabular}

10. If yes to question one, briefly describe the response you have received from faculty.

\begin{tabular}{|c|}
\hline Answer \\
\hline "Positive. Some faculty have expressed concerns about copyright." \\
\hline "Good so far. Too new to really know." \\
\hline
\end{tabular}


11. If yes to question one, briefly describe the response you have received from students.

\begin{tabular}{|c|}
\hline Answer \\
\hline "Extremely positive. However, they have expressed a preference to \\
be able to download tracks and/or have mobile access."
\end{tabular}

12. If yes to question one, has your in-house usage been affected by streaming?

\begin{tabular}{|c|c|}
\hline Answer & Response Count \\
\hline Yes & 1 \\
\hline No & 2 \\
\hline Skipped question & 3 \\
\hline
\end{tabular}

13. If yes to question one: Copyright is a hot topic with regard to streaming. Please describe below how your library handles copyright issues with regard to streaming.

\begin{tabular}{|c|c|}
\hline Answer & Response Count \\
\hline Authentication & 1 \\
\hline On campus access only & 1 \\
\hline Skipped question & 4 \\
\hline
\end{tabular}

14. If yes to question one, do you limit what works you will stream?

\begin{tabular}{|c|c|}
\hline Answer & Response Count \\
\hline Yes & 1 \\
\hline No & 2 \\
\hline Skipped question & 3 \\
\hline
\end{tabular}

15. If yes to question one, do you limit how much of an individual work you will stream?

\begin{tabular}{|c|c|}
\hline Answer & Response Count \\
\hline
\end{tabular}




\begin{tabular}{|c|c|}
\hline Yes & 1 \\
\hline No & 2 \\
\hline Skipped question & 3 \\
\hline
\end{tabular}

16. If yes to question one, do you limit who can request items to be streamed?

\begin{tabular}{|c|c|}
\hline Answer & Response Count \\
\hline Yes & 2 \\
\hline No & 1 \\
\hline Skipped question & 3 \\
\hline
\end{tabular}

17. If yes to question one, do you stream items that are not held in the library collection?

\begin{tabular}{|c|c|}
\hline Answer & Response Count \\
\hline Yes & 2 \\
\hline No & 0 \\
\hline Skipped question & 4 \\
\hline
\end{tabular}

18. Do you have any comments or feedback that you would like to share?

RECEIVED: January 20, 2010

REVISED: $\quad$ February 19, 2010

ACCEPTED: $\quad$ February 22, 2010

James Mason works as Music Librarian at the University of Toronto's Music Library. Jared Wiercinski is Digital Services \& Outreach Librarian at Concordia University. 